\title{
Myopericarditis: Physiopathological Consideration and Image Diagnosis-A Case Report
}

\author{
Santiago de Dios, Alfonso Jurado, Jaime Fernandez \\ Department of Cardiology, Hospital de la Zarzuela, Madrid, Spain \\ Email: drdedios@gmail.com, alfonjroman@hotmail.com, jfernandezcuadrado@gmail.com
}

Received 28 June 2014; revised 30 July 2014; accepted 16 August 2014

Copyright (C) 2014 by authors and Scientific Research Publishing Inc.

This work is licensed under the Creative Commons Attribution International License (CC BY). http://creativecommons.org/licenses/by/4.0/

c) (i) Open Access

\begin{abstract}
Myocarditis is a disease whose diagnosis is based on the detection of inflammation. It is usually made by the finding of myocardium damage markers (usually troponin and CPK). Inflammation can also be detected in image tests. However, the low sensitivity and specificity of echocardiogram (which can be performed as a routine) make it less useful. We present a case in which the diagnosis was made by image (Cardiac Magnetic Resonance) which helped to clarify the evolution and the prognosis. The aim of this case is to show the importance of image technics in the diagnosis of myocarditis, while biomarkers alone can underestimate the inflammation and therefore the risk.
\end{abstract}

\section{Keywords}

\section{Myopericarditis, Cardiac Magnetic Resonance}

\section{Background}

Myopericarditis is an inflammatory disease that affects both pericardium and myocardium. Diagnosis of pericarditis is based on clinical (pleuropericardial chest pain, pericardial friction) electrocardiographic (ST changes, PR) and even echocardiographic (pericardial effusion) criteria, though this last one is not always performed (at least not in a first not complicated clinical presentation) and ECG also has the aim of discard other chest pains causes (mainly ischemia) [1]. However, though infrequent but clearly worsens the prognosis, the addition of the diagnosis of myocarditis is made by analytical criteria, finding myocardium damage markers elevation (usually troponin and (PK). In fact, this is myocardium damage and its relation to the appearance of arrhythmias and ventricular dysfunction what makes compulsory the hospitalization, monitorization and intense treatment of the inflammation until the normalization of the process. 
Therefore, myopericarditis includes both diagnosis and in general is not a comparable process with the evolution of a myocarditis where the myocardium is the mainly affected, but rather an extension of the inflammation from the pericardium to the adjacent myocardium, and has a clearly better clinical evolution.

\section{Case Report}

We present the case of a 32-year-old woman, who begins with suggestive pericarditis symptoms, normal ECG and negative myocardium damage markers, even normal C-reactive protein, but as the symptoms were clear, we started antiinflammatory treatment (NSAID) with slow but favorable evolution. The echocardiogram (Figure 1) performed showed moderate pericardial effusion though quite located mainly inferior to Right Ventricle and Right atrium, especially at the atrioventricular groove. Despite complete conventional treatment, even after adding colchicine, the symptoms persisted. A Cardiac Magnetic Resonance (Figure 2) was performed showing clear acute inflammatory signs at myocardium at the same level as the pericardial effusion (interstitial edema), so the diagnosis was changed to myopericarditis.

Next 6 months included periods when we could diminish the amount of NSAID without reaching complete suspension with other periods of prolonged hospitalization even assaying high dose corticoids to allow discharge. Now the patient is under treatment with dexketoprofen and colchicine with acceptable symptomatic control. Echocardiograms where performed frequently with wide or narrow effusion according to the symptoms, and always in the same place. CMR was performed 3 months after the first one, without any relevant change in the inflammatory signs.

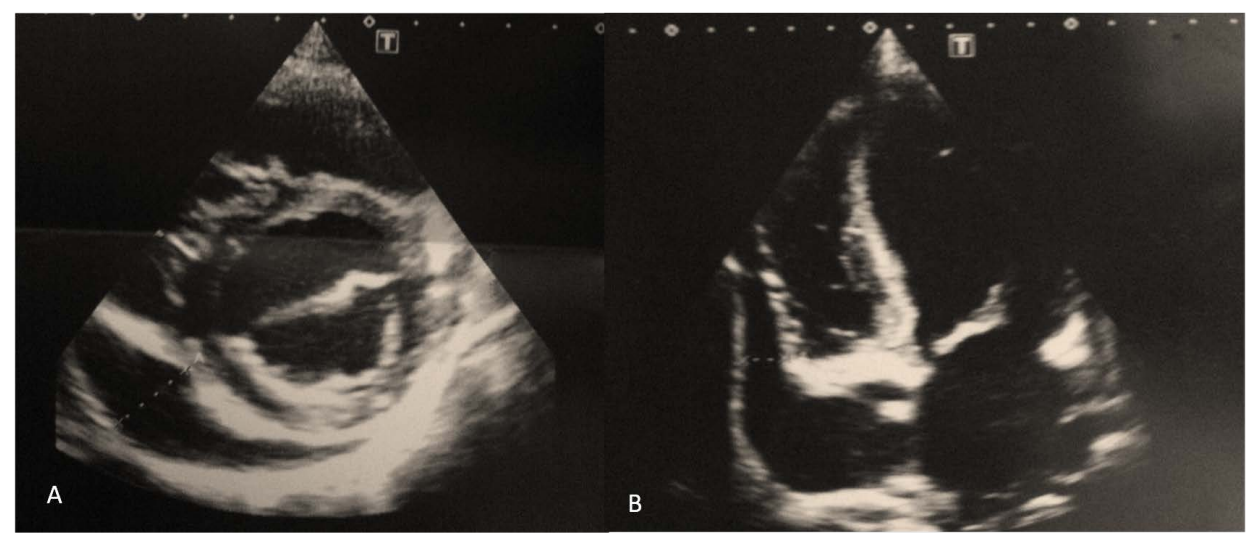

Figure 1. Echocardiogram at the diagnosis. (A) Parasternal short axis view showing moderate pericardial effusion. (B) Modificated 2 chamber view, showing a posterior pericardial effusion.

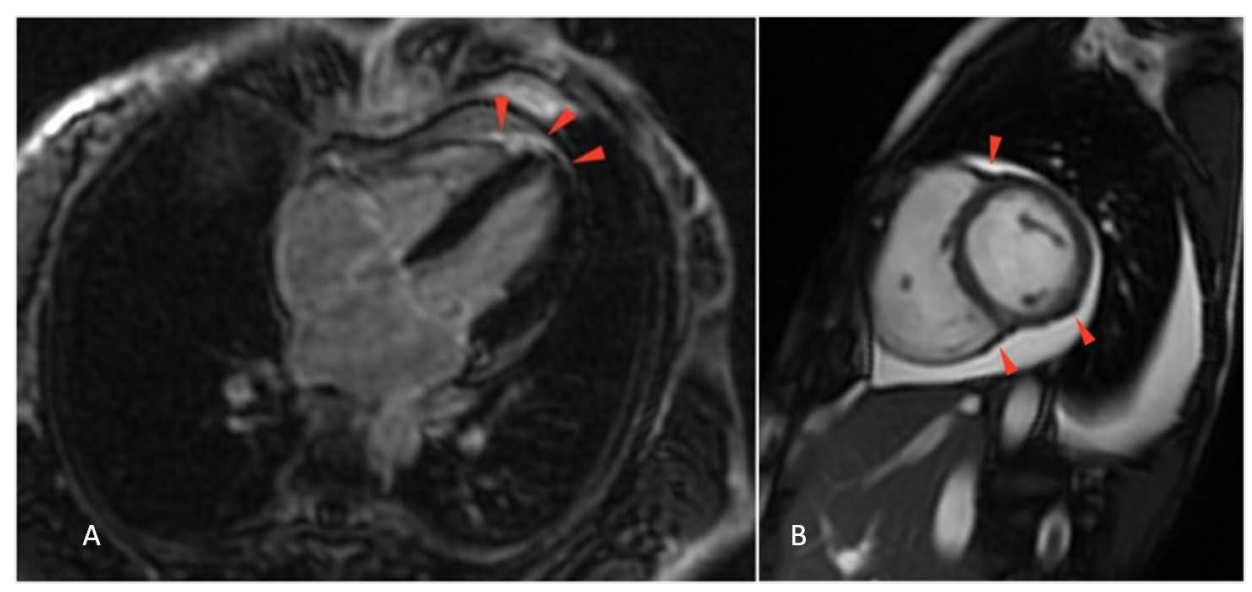

Figure 2. Cardiac Magnetic Resonance performs at the diagnosis. (A) Red arrows point late gadolinium enhancement at myocardium showing the interstitial edema. (B) Pericardial effusion coinciding with the affected myocardium. 


\section{Discussion}

In our case report, the myopericarditis diagnosis was made by image, not by analytical findings, and the poor clinical response was accompanied by the absence of evolution in the inflammatory signs in the CMR. It does not seem feasible (neither economically sustainable) to perform a CMR in patients with pericarditis to discard the presence of myocarditis, although it is possible that it has a prognosis value in those with a torpid evolution as our case.

The presence of interstitial edema and the maintenance of inflammation for prolonged periods have been related to development of constriction and ventricular arrhythmias [2] [3] so detection of this signs could have a prognostic impact, reason why we recommend to perform a CMR in these patients.

Other similar cases are described in the literature, and even the surgery (pericardiectomy) is performed in selected cases due to its evolution [4]. Fortunately, such a symptomatic clinical presentation is infrequent, what makes difficult to perform larger studies to prove the utility of wider use of CMR [5] [6].

\section{References}

[1] Masek, K. and Levis, T. (2013) ECG Diagnosis: Acute Pericarditis. The Permanente Journal, 17, Article ID: e146.

[2] Scott, P.A., Rosengarten, J.A., Curzen, N.P. and Morgan, J.M. (2013) Late Gadolinium Enhancement Cardiac Magnetic Resonance Imaging for the Prediction of Ventricular Tachyarrhythmic Events: A Meta-Analysis. European Journal of Heart Failure, 15, 1019-1027. http://dx.doi.org/10.1093/eurjhf/hft053

[3] Kuruvilla, S., Adenaw, N., Katwal, A.B., Lipinski, M.J., Kramer, C.M. and Salerno, M. (2014) Late Gadolinium Enhancement on Cardiac Magnetic Resonance Predicts Adverse Cardiovascular Outcomes in Nonischemic Cardiomyopathy: A Systematic Review and Meta-Analysis. Circulation: Cardiovascular Imaging, 7, 250-258. http://dx.doi.org/10.1161/CIRCIMAGING.113.001144

[4] Leurent, G. (2010) Management and Prognosis of Myopericarditis. International Journal of Cardiology, $141,192$. http://dx.doi.org/10.1016/j.ijcard.2008.11.065

[5] Ariyarajah, V., Jassal, D.S., Kikpatrick, I. and Kwong, R.Y. (2009) The Utility of Cardiovascular Magnetic Resonance in Contrictive Pericardial Disease. Cardiology in Review, 17, 77-82. http://dx.doi.org/10.1097/CRD.0b013e318197e950

[6] Hoffmann, E., Alcamisi, G.P., Finazzo, M. and Midiri, M. (1998) The Role of Nuclear Magnetic Resonance in the Diagnosis of Pericardial Disease. Cardiologia, 43, 581-587. 
Scientific Research Publishing (SCIRP) is one of the largest Open Access journal publishers. It is currently publishing more than 200 open access, online, peer-reviewed journals covering a wide range of academic disciplines. SCIRP serves the worldwide academic communities and contributes to the progress and application of science with its publication.

Other selected journals from SCIRP are listed as below. Submit your manuscript to us via either submit@scirp.org or Online Submission Portal.
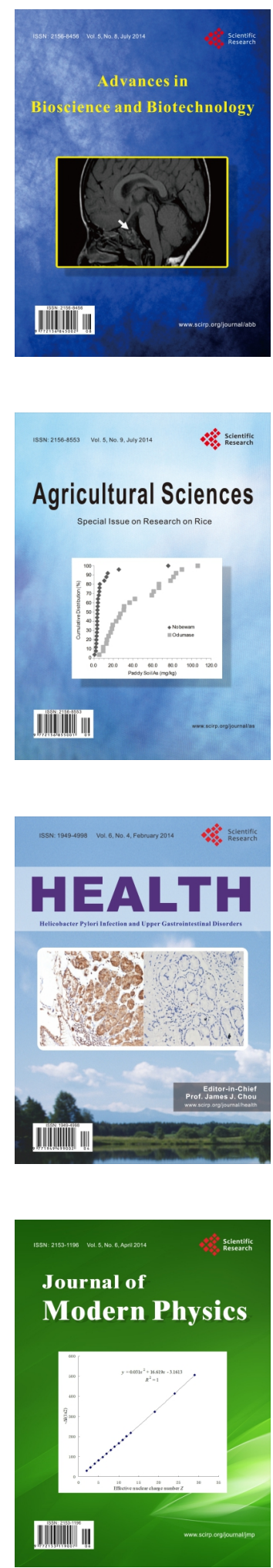
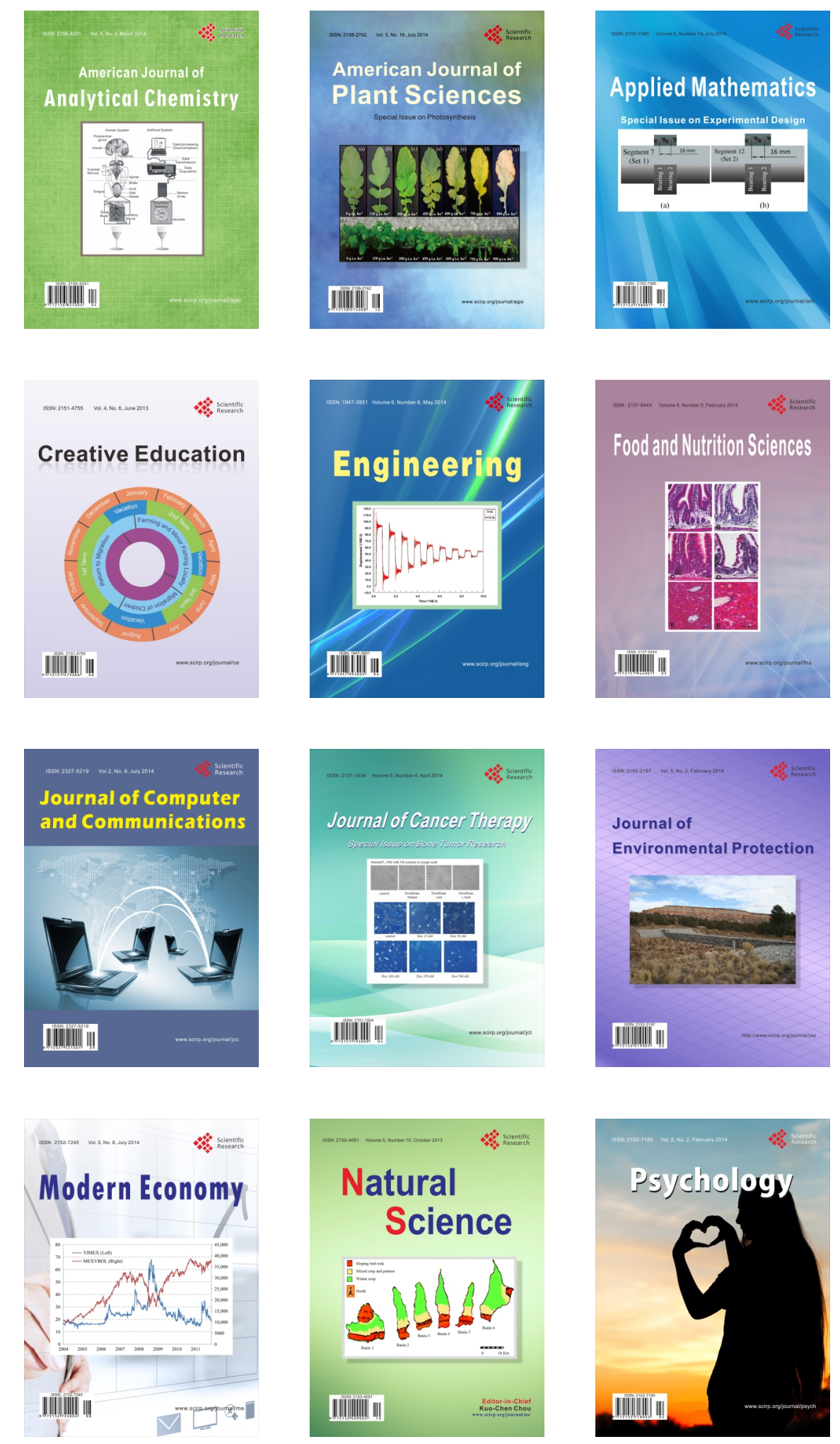